\title{
Examining legitimatisation of additive manufacturing in the interplay between innovation, lean manufacturing and sustainability
}

Article

Accepted Version

Creative Commons: Attribution-Noncommercial-No Derivative Works 4.0

Ghobadian, A., Talavera Fabra, I., Bhattacharya, A., Kumar, V., Arturo Garza-Reyes, J. and O'Regan, N. (2020) Examining legitimatisation of additive manufacturing in the interplay between innovation, lean manufacturing and sustainability. International Journal of Production Economics, 219. pp. 457468. ISSN 0925-5273 doi:

https://doi.org/10.1016/j.ijpe.2018.06.001 Available at https://centaur.reading.ac.uk/77833/

It is advisable to refer to the publisher's version if you intend to cite from the work. See Guidance on citing.

To link to this article DOI: http://dx.doi.org/10.1016/j.ijpe.2018.06.001

Publisher: Elsevier

All outputs in CentAUR are protected by Intellectual Property Rights law, including copyright law. Copyright and IPR is retained by the creators or other copyright holders. Terms and conditions for use of this material are defined in the End User Agreement. 


\section{www.reading.ac.uk/centaur}

\section{CentAUR}

Central Archive at the University of Reading

Reading's research outputs online 


\title{
Examining Legitimatisation of Additive Manufacturing in the interplay between Innovation, Lean Manufacturing and Sustainability
}

\begin{abstract}
In response to hypercompetition, globalisation and increasing consumer expectations, many manufacturing firms have embraced lean manufacturing (LM). The primary goal of LM is to reduce/eliminate waste (muda). There is broad consensus as to what constitutes waste, but not on LM implementation. Implementation is not prescriptive with each firm relying on a different combination of administrative, process and routine change / innovation. Lean manufacturing brings about incremental change relying on administrative, process and routine levers. It best fits mass production where process variability is low and demand is high and stable. Lean manufacturing can significantly reduce waste but not eliminate waste, and the attained benefits have not always lived up to expectations. Additive manufacturing (AM) promises to revolutionise manufacturing beyond recognition by eliminating or drastically removing the waste thereby achieving sustainability. But AM is at its formative stage - the space between the concept and growth - where many promising breakthrough technologies fail. To reach its full potential, it needs to achieve high-scale adoption. In this paper, we examine how AM can significantly reduce/eliminate waste and how it can deliver triple bottom line on an unprecedented scale. We contend that AM, if adopted deeply and widely, will take LM to its final frontier, but there are a number of impediments to this end. We identify legitimation as critical to its wide diffusion and develop a number of propositions expediting AM's legitimation. Legitimation of AM will ensure its deep and broad diffusion and should this happen, waste will be a thing of the past an important stride towards sustainable future.
\end{abstract}

Keywords: Lean manufacturing; Additive manufacturing; 3D printing; Sustainability; 
Innovation; Legitimation.

\section{Introduction}

Lean manufacturing (LM) is extensively deployed, particularly by firms operating in stable environments producing standard products at high volumes, to partially alleviate the negative impact of hypercompetition, increasing customer expectations and globalisation on competitiveness (Yadav et al., 2017). The concept first appeared in an article entitled 'Triumph of the lean production system' (Krafcik, 1988) and was further popularised by the book The Machine That Changed the World (Womack et al., 1990). In essence, LM builds on and extends the Toyota Production System (TPS) ideas (Ohno, 1989). The central aim of LM is the elimination of all unnecessary sources of process waste (muda) in order to reduce costs, improve efficiency, increase flexibility and maximise the generation of value to customers (Bevilacqua et al., 2017). More recently, drawing on the industrial ecology, LM has embraced process damage to the physical environmental and excessive use of natural resources as additional sources of waste (Simboli et al., 2014). As we point out in Section 2, LM seeks to incrementally reduce waste relying on altering structure (for example, level of autonomy), modifying or introducing new processes (for example, mixed mode processing, rank order clustering (cell production), single-minute exchange of die (SMED) or just-in-time (JIT)) and new routines (for example, six sigma, total productive maintenance, or poka-yoke).

Additive manufacturing (AM) or three-dimensional (3D) printing is a breakthrough technology promising to almost entirely eliminate waste targeted by LM, including that which harms the environment or lessens sustainability. Furthermore, AM arguably can broaden waste elimination reaching firms deploying jobbing or batch processes, where LM has limited applicability and impact, as well as deepen its reach by touching mass producers in sectors where LM is a rarity (see the example of Adidas). Firms using jobbing or batch processes are 
more numerous forming the backbone of mass producers supply chain. Unlike traditional manufacturing - which builds objects by cutting, bending and bashing materials and joining parts together using welding, soldering, riveting, screwing or gluing - AM builds objects by depositing material layer by layer. The change from subtractive to additive fundamentally alters the manufacturing paradigm facilitating the elimination of waste targeted by LM (see Table 1 for categories of waste targeted by LM and for the potential impact of AM on elimination of waste tackled by LM refer to Section 3, and Table 3). However, as we point out in Section 3, $\mathrm{AM}$ is in its formative phase and most breakthrough technologies fail at their formative phase (Stevens \& Burley, 1997). We contend that broadly diffused AM facilitates the elimination of waste targeted by LM, while LM in its current forms can only incrementally reduce waste (see Fig. 1). As such, AM represents the ultimate innovation in LM broadening its application from mass to jobbing and batch production, deepening its reach by touching mass producers hitherto unaffected by LM, and intensifying its impact by eliminating rather than reducing waste targeted by LM. We contend that AM represents the frontiers of LM and as such AM subsumes $\mathrm{LM}$, that is, for the purpose of process waste elimination AM and LM are overlapping and interchangeable. The question we address in this paper is how to move AM from the formative to the growth phase. The answer to this question is of significant importance to the future practice of LM because: (a) AM offers a technological solution capable of eliminating process waste; and (b) it makes LM a reality for jobbing and batch manufacturers (see Section 3).

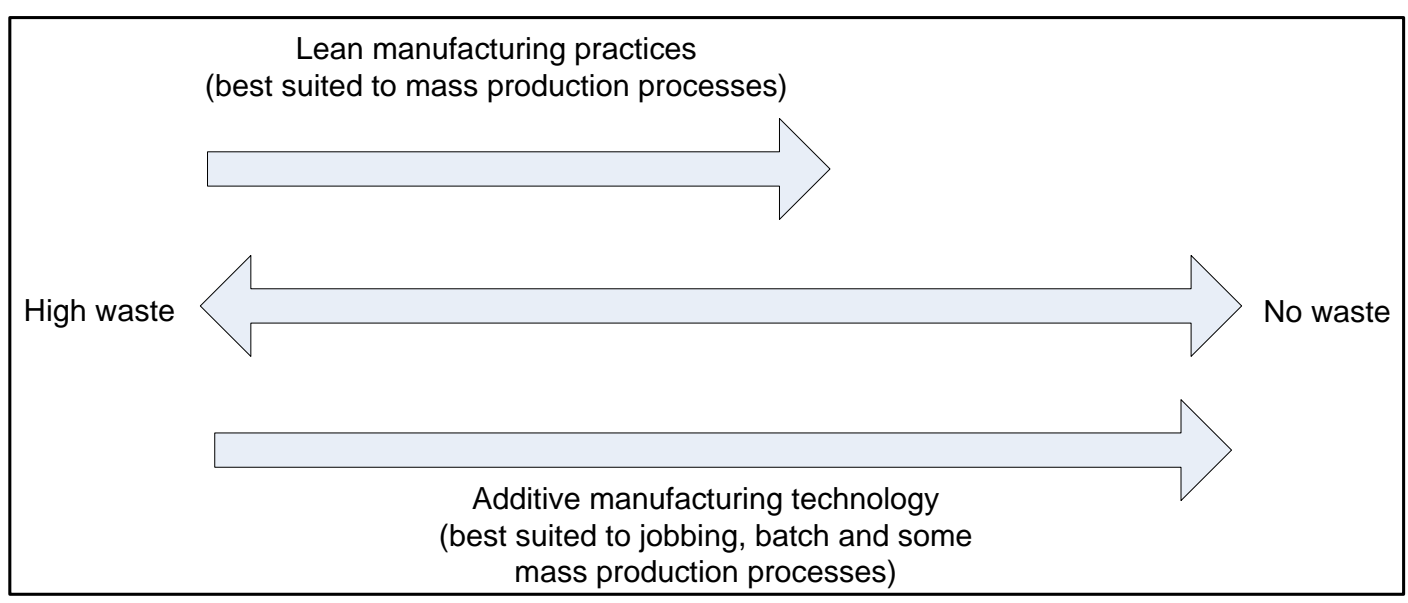


Fig. 1: Potential impact of lean and additive manufacturing on waste (muda)

To answer our research question, we establish a link between LM's central concept the elimination of process waste including damage to the physical environment and unnecessary use of resources - and AM. We contend that LM practices help manufacturers, in particular mass producers, to reduce process waste but AM enables a broader group of manufacturers to eliminate waste (see Fig. 1). We demonstrate how AM can potentially eliminate waste, facilitating attainment of LM's ultimate goal particularly among manufacturers deploying jobbing or batch processes. However, AM is in its formative phase and unless it is managed it will not reach the scale of adoption necessary for it to leave a significant and lasting legacy - improving manufacturers economic performance by eliminating waste, reducing harm to the physical environment and enhancing sustainability. More significantly, we argue that legitimation is critical to the deep and broad adoption of AM offering a number of propositions underpinning the AM's legitimation process (see Section 5 for definition).

Lean manufacturing offers an innovative change (Berente \& Lee, 2014). Change is either episodic and revolutionary, or incremental and evolutionary (Pettigrew et al., 2001). Biazzo et al. (2016) suggest that LM offers incremental rather than radical change, while AM promises radical change. Dimensions of organisational change and innovation include: structure (e.g. control, power distribution, etc.), process (e.g. organisation of transformative activities), routine (e.g. organisational policy and practices), or technology (Pettigrew et al., 2001). Lean manufacturing implementation is predominately reliant on introduction of new routines and to a lesser extent processes or technology (Yadav et al., 2017; Jasti \& Kodali, 2015). Change to routines or introduction of new routines is likely to alter the process waste metrics gradually. On the other hand, AM offers a technological solution to the process waste problem. Technological change, if successfully implemented, is capable of eliminating or 
generating substantial positive shifts in the process waste metrics. Lean manufacturing, as it stands, offers a better fit in situations where the demand for products is high, the operating environment is stable (making forecasts less risky), processes are repetitive, and process variability is low and controllable (Browning \& Sanders, 2012). These conditions are best served by mass production processes. Mass producers are more likely to make parts and products based on forecasts rather than to order, which as a rule, is more prevalent among jobbing and batch manufacturers. Olhager \& Prajogo (2012) found that deployment of LM improved the performance of manufacturers making to forecast and not those making to order. This supports Browning \& Sanders (2012) point and suggests that LM has a limited impact on manufacturers using jobbing or batch processes. Additive manufacturing potentially can reach and transform parts of the manufacturing industry (those deploying jobbing or batch processes) that are more difficult to reach with the traditional LM tools and practices.

Despite more than four decades of experience with LM, its introduction does not always produce the desired outcome (Marodin \& Saurin, 2013; Marvel \& Standridge, 2009). Many of the barriers to the successful implementation of LM are people related; for example, the level of attention by mangers (Marodin \& Saurin, 2015). Cultural- and people-related issues are deep seated and difficult to overcome (Marodin \& Saurin, 2015). Appropriate, well planned and implemented technological solutions, although not free of people and cultural issues, are less likely to be blown off course by them (Bate, 1984). Additive manufacturing represents a breakthrough technological innovation with the promise of overcoming some of the obstacles prohibiting full realisation of LM goals - the elimination of process waste, resulting from nonvalue adding actions. However, this will only happen if AM reaches a significant scale of adoption.

In this article, we examine AM's capabilities from its innovation and sustainability perspectives. Once the link between LM and AM is established, we offer a set of propositions 
promoting AM's legitimacy - that is, winning acceptance of all the relevant actors and stakeholders (see Section 5 for full definition). We contend that once AM gains legitimacy it will be adopted by a significant number of manufacturers deploying jobbing or batch production processes as well as enabling new entrants to leapfrog the jobbing shop process stage. This is a reinforcing circle because wide adoption of AM will reduce waste and reduce negative environmental externalities as well as enhancing sustainability. We also contribute to the AM literature by drawing out how it might be legitimated so it can move from the formative to the growth phase. We also contribute to practice and policy by highlighting the elements contributing to the legitimation of AM.

The rest of this paper is organised as follows. In Section 2, we briefly review aspects of LM pertinent to our study. Section 3 presents a general discussion centred on the link between LM and AM and the evidence supporting the assertion that AM represents an innovative capability in the context of LM that improves sustainability. Section 4 is devoted to a review of the potential contribution of AM to LM sustainability under each dimension of the triple bottom line (Elkington, 1997) together with current barriers preventing a deep and broad diffusion. This is followed by a set of propositions in section 5. Finally, a summary and conclusions are presented in sections 6 and 7 respectively.

\section{Lean Manufacturing}

Lean manufacturing has been deployed for more than four decades. The literature covering LM is vast (Yadav et al., 2017). A broad review of this literature falls outside the scope of this paper. For those interested, there are number of excellent reviews (e.g. Jasti \& Kodali, 2015; Marodin \& Saurin, 2013; Yadav et al., 2017). The aim of this brief review is to identify the central aim of LM, pinpoint what LM considers as process waste, identify the key implementation issues and outline the operating conditions that best support LM. 
According to the extant literature, the incontrovertible aim of LM is to remove/reduce process waste (Bevilacqua et al., 2017; Womack \& Jones, 1996). Waste constitutes any resource used for any purpose other than the creation of value (Yadav et al., 2017; Womack \& Jones, 1996). The extant literature has identified a large number of sources of waste. In Table 1, we summarise sources of waste identified through an extensive literature review (Jasti \& Kodali, 2015) and an extensive study of the TPS often credited as the foundation of LM (Liker, 2004). Despite using slightly different terminology, the comparison between the outcome of an extensive literature review and an authoritative book suggests broad agreement in terms of the sources of process waste and their description.

Table 1: Sources of waste and their definition

\begin{tabular}{|c|c|c|}
\hline $\begin{array}{l}\text { Jasti \& Kodali } \\
\text { (2015) }\end{array}$ & Liker (2004) & Broad definition \\
\hline Defects & Defects & $\begin{array}{l}\text { Any type of rework or repair, as well as excessive scrap is } \\
\text { considered waste. }\end{array}$ \\
\hline $\begin{array}{l}\text { Unnecessary } \\
\text { inventory }\end{array}$ & Excess inventory & $\begin{array}{l}\text { Excess inventory of parts, sub-assemblies or finished } \\
\text { goods. }\end{array}$ \\
\hline Waiting & Waiting time & $\begin{array}{l}\text { Idle production machinery due to stock-outs, processing } \\
\text { delays, scheduling mishaps, capacity bottlenecks, etc. }\end{array}$ \\
\hline Transportation & $\begin{array}{l}\text { Unnecessary } \\
\text { transportation }\end{array}$ & $\begin{array}{l}\text { Moving finished goods or parts unnecessarily long } \\
\text { distances. }\end{array}$ \\
\hline $\begin{array}{l}\text { Inappropriate } \\
\text { processing }\end{array}$ & $\begin{array}{l}\text { Over processing or } \\
\text { incorrect processing }\end{array}$ & $\begin{array}{l}\text { Unnecessary steps to produce goods, for example, due to } \\
\text { poor design, limitations of available equipment, } \\
\text { excessively high quality standards, etc. }\end{array}$ \\
\hline Over production & Over production & Production of goods for which there are no orders. \\
\hline \multirow[t]{2}{*}{$\begin{array}{l}\text { Unnecessary } \\
\text { motions }\end{array}$} & $\begin{array}{l}\text { Unnecessary } \\
\text { movement }\end{array}$ & $\begin{array}{l}\text { Excessive (in terms of both frequency and distance) or } \\
\text { unnecessary movement of people, parts or finished goods. }\end{array}$ \\
\hline & $\begin{array}{l}\text { Unused employee } \\
\text { creativity }\end{array}$ & Not fully utilising employees' skills and ideas. \\
\hline
\end{tabular}

Lean manufacturing is a moving entity, an evolving concept (Hines et al., 2004). With 
the rise of environmental concerns and popular demand for environmental protection, the sources of waste (muda or non-value) presented in Table 1 have been extended to encompass what is defined by industrial ecology as environmentally harmful (scrap, excessive use of energy, transportation, emissions, effluents and wastes created during manufacturing of goods) and the overuse of natural resources (Simboli et al., 2014). In this paper, we use the sources of waste identified by Jasti \& Kodali (2015) and add to them environmental harm and sustainability in keeping with the more recent notion of muda (see Table 2). The inclusion of environmental harm and sustainability recognises externalities of manufacturing by extending the notion of muda to include society as well as customers. However, it is important to point out that muda, by reducing/removing activities not adding value to customer also reduces environmental harm. Table 2 provides an explanation as to how the removal/reduction of the seven categories of waste identified by Jasti \& Kodali (2015), and used later in this paper, reduce environmental harm.

Table 2: Impact of reducing waste on the physical environment (adapted from Simboli et al., 2004)

Original sources of waste (muda) Physical environmental impacts

Defects

Unnecessary inventory

Waiting

Transportation
- Unnecessary consumption of raw material and energy in making defective products

- Defective components/products require recycling or disposal

- Additional floor space for rework and repair, increasing energy use for heating, cooling and lighting

- Additional use of packaging material to store work in progress (WIP)

- Waste from deterioration or damage to stored WIP and use of more material to replace damaged WIP

- More energy used to heat, cool and light inventory space

- Potential material spoilage or component damage causing waste

- Wasted energy from heating, cooling and lighting during production downtime

- Energy and fuel used for unnecessary transport

- Emissions from unnecessary transport 


\begin{tabular}{|c|c|}
\hline Inappropriate processing & $\begin{array}{l}\text { - More raw material and parts consumer per unit of } \\
\text { production } \\
\text { - Unnecessary processing increases waste, energy use and } \\
\text { emissions }\end{array}$ \\
\hline Over production & $\begin{array}{l}\text { - More raw materials and energy consumed in making } \\
\text { unnecessary products } \\
\text { - Obsolescence and spoilage of extra products requiring } \\
\text { disposal } \\
\text { - Disposal of unwanted overruns putting pressure on } \\
\text { landfills } \\
\text { - Extra emission, energy use }\end{array}$ \\
\hline Unnecessary motions & $\begin{array}{l}\text { - Additional packaging required to protect } \\
\text { products/components during movement } \\
\text { - Spill during movement producing environmental } \\
\text { damage } \\
\text { - Risk of accidents and goods damage }\end{array}$ \\
\hline
\end{tabular}

By attacking waste, LM reduces the negative impact on the physical environment. Although, as it was pointed out in the introduction, the relevance of LM beyond mass production and stable business environments is questioned (Bevilacqua et al., 2017; Browning \& Sanders, 2012). Hence, any environmental benefit arising from LM is unlikely to significantly affect firms deploying jobbing or batch process. We point out in Section 3 that not only can AM make a difference to firms deploying jobbing and batch processes but it is also capable of eliminating the sources of waste listed in Table 2, offering a more profound impact on the physical environment. Finally, AM's impact goes beyond the sources of waste listed in Table 2, offering additional positive externalities (see Section 3).

Tools and practices underpinning LM are numerous (Shah \& Ward, 2007). Jasti \& Kodali (2015) identify 26 tools and practices underpinning LM, while Marodin \& Saurin (2013) identify 37 tools and practices. Reviewing these tools and practices falls outside the remit of this paper. It suffices to state that LM has evolved from the original and relatively simple TPS - relying primarily on two sets of broad practices/tools namely just-in-time (JIT) and jidoka (Ohno, 1989) - to embracing a large number of tools and practices resulting in lean business systems (Hines et al., 2004). A number of major multinationals, for example, 
Caterpillar, Heinz and Johnson Controls, have developed their own proprietary lean programmes. Implementing LM often entails deployment of multiple tools and practices (Jasti \& Kodali, 2015; Marodin \& Saurin, 2013). This in turn increases complexity, which arguably accounts for below-expectation outcomes (Marodin \& Saurin, 2015). For example, Baker (2002) concludes that less than 10 per cent of British and Australian firms that implemented LM attained a high level of leanness. Similarly, Blanchard (2007) concluded that, based on a survey of 433 American firms, less than a third of them attained substantial gains from implementing LM, and Marvel \& Standridge (2009) also concluded that few organisations have achieved substantial improvements as a consequence of implementing LM.

Based on the literature review and the above summary, we contend that: (a) the extant literature is united in identifying the primary goal of LM as the reduction/removal of waste; (b) waste is considered as any process or activity/action therein that does not create value for the customer or wider society; (c) there is broad agreement in terms of categories of waste; (d) LM has evolved and its implementation entails simultaneous deployment of a multitude of tools and practices; and (e) there is a substantial negative gap between expected and actual outcomes.

\section{Additive Manufacturing and Lean Approach}

Additive manufacturing, or 3D printing, is an umbrella term covering a suite of emerging technologies that fabricate 3D objects directly from digital models by depositing and joining layer upon layer of polymers, ceramics or metals (Ford, 2014). The technology first emerged in 1987 to make prototypes, but AM has improved to the extent that it is now used to provide cost- and time-efficient, low-volume customised products with complicated geometries and advanced material properties and functionality (Huang et al., 2015). Wohlers \& Caffrey (2015) provide a succinct chronology of AM's technological development. The potential promise of AM is attracting unprecedented attention from scholars, policy makers and industry. The 
number of predominately technically oriented AM articles published increased from 1,600 in 2011 to 16,000 in 2012 (Ford, 2014). Policy makers consider it as an important tool to strengthen productivity and competitiveness - the former US president, Barack Obama, extolled the potential of AM in his 2012 State of the Union address, stating it could 'revolutionise the way we make almost everything', and the White House Office of Science and Technology Policy has formed an interagency working group. Industrialists are convinced that AM has the potential to change the face of the manufacturing industry $(F T, 2016)$. Its potential is creating an unprecedented level of expectation and excitement heralding the arrival of the Third Industrial Revolution (Berman, 2012; Economist, 2012; Rifkin, 2012).

Conventional manufacturing starts with raw material creating the desired object by cutting, drilling, milling, casting, joining, etc. Any subtractive process inevitably generates scrap while an additive process only uses the material necessary to make an object. Hence, AM inherently creates less waste than the traditional manufacturing processes. The creation of an object, even a simple one, requires several steps; hence, in conventional manufacturing, raw material and part-formed objects are moved from machinery to machinery forming queues of WIP, defects due to processing complexity and human error, and over production (Slack et al., 2009). Hence, movement, waiting, inventory, defects and overproduction are part and parcel of jobbing and batch manufacturing processes. Moreover, production of a different product entails tool changes and machine set-up, a non-productive activity according to LM principles. As mentioned, jobbing and batch environments are not good candidates for applying LM. Mass production is not exempt from producing defective products, over production, movement, waiting, WIP and an inventory of finished goods (Slack et al., 2009). However, applying the tools and practices of LM can and does reduce waste. For example, JIT separates supply from demand, thus reducing the need to hold large component stocks, while operating a pull system reduces risks of over production. However, it arguably moves the stock holding back to first- 
tier suppliers, etc. So, even in the case of mass production, LM implementation reduces but does not eliminate process waste and sometimes it moves waste back to the first-tier suppliers.

Additive manufacturing, on the other hand, starts with a blank page and adds layers according to instructions from a computer programme containing the virtual representation of the object to be made. By changing the software, AM equipment can produce a different object. Hence, there is no scrap, no movement, no inventory, no machine set-up, and no defects - that is no waste. The extant literature points to the potential socioeconomic benefits of AM; chief among them is the disruptive shake-up of the entire supply chain, allowing firms to print much of what they need rather than order it, often from overseas. Manufacturing parts and products close to the point of use allows manufacturing firms to further decentralise and redistribute manufacturing, making products on a small scale close to the point of use - an organisational paradigm shift from flexible specialisation to redistributed manufacturing. Caterpillar and John Deere are working with Carbon on moving their warehouses, in effect, to the online cloud, from where digital designs can be downloaded to different locations (distributed manufacturing) for parts to be printed to order (Economist, 2017a). If successful, this project will remove the need for holding stock, with the effect of reducing the warehousing space drastically, removing the need for transportation and movement, shortening supply lead times, etc., all contributing to the elimination of waste and reduction of physical environmental damage. The $F T$ (2016) uses an analogy with ticket sales to demonstrate the potential benefit of AM by stating that: 'any concert-goer knows it is easier to print tickets than pick them up or hope they arrive in the post. Businesses soon will realise the same applies to spare parts, equipment and electronics.' Bosch Rexroth, the drive and control unit of a private German electronics group, projects that in five to ten years 40 per cent of the manufacturing equipment it uses will be printed instead of purchased, making equipment manufacturing 60 per cent cheaper than the conventional method used today $(F T, 2016)$. General Electric (GE) uses AM 
to print fuel nozzles for the new LEAP jet engine (Economist, 2017a). The nozzles have new features and cannot be manufactured using conventional technology. By printing them as a single structure, they avoid welding 20 or more components together; they are 25 per cent lighter, saving fuel; and five times more durable, reducing service costs (Economist, 2017a). GKN Aerospace is collaborating with Oak Ridge National Laboratory to find new ways of printing large structural parts in titanium to reduce material waste by as much as 90 per cent and to cut assembly time in half (Economist, 2017a). Adidas is building a factory in Germany and one in the USA, each producing 50,000 pairs of trainers using computerised knitting, robotic cutting and AM (Economist, 2017b). An order to replenish a popular trainer currently takes two to three months to reach the shelf, often requiring air transport as well as overruns (Economist, 2017b). The new factory will reduce lead time to less than a week by shortening the supply chain (instead of ordering components and assembling them into a new pair of trainers, the new factory will make most of the parts itself from raw materials), reducing the processing steps, minimising movement, reducing transportation and improving reliability. These examples are indicative of AM's potential breadth of usage, as well as demonstrating the potential for AM to eliminate process waste targeted by LM and its positive environmental and sustainability externality.

\subsection{Potential impact of AM on lean manufacturing waste categories}

The extant literature suggests the following as the potential benefits of AM (Foresight, 2013; Huang et al., 2013; Kietzmann et al., 2015):

- reducing time to market

- drastically lowering set-up times, making the manufacture of a batch of one economically viable

- Significantly reducing processing steps

- eliminating scrap, reducing the need for material and easing pressure on landfill sites 
- reducing energy requirements

- improving quality and reducing the need for re-work and scraping part-finished components

- making the manufacture of complex parts possible - creating new markets

- reducing total production costs

- making in-house manufacture of parts and products a reality - shortening supply chains and reducing the need for transport

- making possible the reshoring of production.

As importantly, AM has the potential to become a multifaceted tool, mitigating negative environmental impacts of manufacturing by replacing many of the casting, moulding and other manufacturing processes that consume significant amounts of energy and produce hazardous industrial waste (Ford, 2014). Furthermore, AM imposes minimal constraints on product design, offering the possibility of manufacturing more efficient lightweight products or the consolidation of previously separate parts into a single object, reducing the amount of energy and natural resources required (Ford, 2014). Finally, other generic benefits such as the ability to print spare parts on demand can significantly reduce the need for holding inventory as well as extending the shelf life of consumer goods. In short, AM's potential impact on the physical environment and sustainability is considerable. Table 3 summarises the impact of AM on categories of waste targeted by LM. This table uses the short cases presented above. Examples and arguments presented in next section further support the veracity of Table 3.

Table 3: Potential impact of additive manufacturing on lean manufacturing waste categories

\begin{tabular}{lll}
\hline Category of waste & $\begin{array}{l}\text { Potential for elimination/significant } \\
\text { reduction }\end{array}$ & Evidence \\
\hline Defects & Close to elimination & GE fuel nozzle \\
Unnecessary inventory & Elimination/close to elimination & Caterpillar cloud
\end{tabular}




\begin{tabular}{|c|c|c|}
\hline & & inventory \\
\hline Waiting & Elimination/close to elimination & $\begin{array}{l}\text { Product made on } \\
\text { a single printer }\end{array}$ \\
\hline Transportation & Significant reduction & $\begin{array}{l}\text { John Deere re- } \\
\text { distributed } \\
\text { manufacturing }\end{array}$ \\
\hline Inappropriate processing & Elimination/close to elimination & $\begin{array}{l}\text { Simulation of } \\
\text { manufacturing } \\
\text { process and } \\
\text { digital testing of } \\
\text { products }\end{array}$ \\
\hline Over production & Elimination/close to elimination & $\begin{array}{l}\text { New Adidas } \\
\text { factories } \\
\text { shortening } \\
\text { supply chain and } \\
\text { lead time to a } \\
\text { week }\end{array}$ \\
\hline Unnecessary motions & Elimination/close to elimination & $\begin{array}{l}\text { Product made on } \\
\text { a single printer }\end{array}$ \\
\hline $\begin{array}{l}\text { Physical environment } \\
\text { externality }\end{array}$ & Significant reduction & GE fuel nozzle \\
\hline Sustainability & Reduced usage of material, energy, etc. & GE fuel nozzle \\
\hline
\end{tabular}

\subsection{Stage of diffusion of AM}

Additive manufacturing is viewed as a key disruptive technology with the potential to change vast swaths of the manufacturing industry (FT, 2016; Economist, 2017a). Assuming it reaches broad- and deep-scale penetration, it will enable firms deploying batch processes to combine the advantages associated with jobbing and mass processes without incurring any of their disadvantages (Economist, 2017c; Ford, 2014). Moreover, it will make the manufacture of one-off goods cheaper and more flexible, by removing the need to tool up and the constraints of traditional manufacturing processes to make things with unique shapes (Economist, 2016). And, as a by-product, it will enable one-off manufacturers to reduce/eliminate waste bringing LM to jobbing shops. Additive manufacturing will not replace the need for assembling goods, but it will change the nature of assemblers' supply chains and in some cases, as with Adidas above, reduce the need for assembly. Additive manufacturing, in reality, will be used to 
manufacture critical components (e.g. engine parts of a car) as opposed to low-value, noncritical parts (e.g. fasteners).

It is important to point out that AM is not yet ubiquitous because it is currently too slow for the production of goods and parts manufactured in high-volume batches, too expensive for some applications and for others it produces results not up to the required standards (Economist, 2017a; Ford, 2014). Such limitations, combined with its current market penetration, discussed in the following paragraphs, suggests that AM is a breakthrough technology in its formative phase.

The market for all AM products and services worldwide was $\$ 2.2$ billion in 2012, a tiny fraction of the total global market (Ford, 2014). However, the year-on-year growth was substantial - up 28.6 per cent from $\$ 1.7$ billion in 2011. A wide range of industries, including automotive, aerospace, medical, industrial machines, electronics, consumer goods and architectural industries use AM to manufacture goods (Ford, 2014). This suggests that AM has the potential to be utilised by many industrial sectors. However, in each case the value of AM products shipped accounts for a small fraction of the total market, that is, between 0.01 to 0.05 per cent of the total shipments by these industries (Ford, 2014). Hence, the depth of penetration in each case is low, pointing to the existence of 'nursing markets' typical of the formative phase (Bergek et al., 2008a). Additive manufacturing machines are installed in many countries including the United States, UK, Germany, France, China, Japan, Russia, Italy, Turkey, Spain, Korea, Taiwan and Canada. The United States accounts for 38 per cent of AM machines; followed by Japan, 10 per cent; Germany, 9.3 per cent; China, 8.6 per cent; UK, 4.3 per cent; Italy, 3.9 per cent; and France, 3 per cent (Ford, 2014). The limitations discussed in the previous paragraph combined with the value of AM products shipped, the broad swathe of manufacturing industries using AM, the large number of AM machine manufacturers and the geographic breadth of installed AM machines suggest that AM, in terms of an innovation life 
cycle, is in its formative phase (See Fig. 2). This is the space between the concept and growth/extensive adoption phases (Bergek et al., 2008a). The formation phase is characterised by high uncertainty, experimentation, variety creation, the commencement of institutional alignment, the formation of early networks and the emergence of rudimentary structures. The high state of flux in the formative phase results in a high failure rate (Stevens \& Burley, 1997). Additive manufacturing is not immune from this rule. Unless the innovation finds legitimacy among the ecosystem players, it will fail to reach the scale of adoption that makes it relevant, that is, it will follow path $\mathrm{B}$ or $\mathrm{C}$ instead of path $\mathrm{A}$.

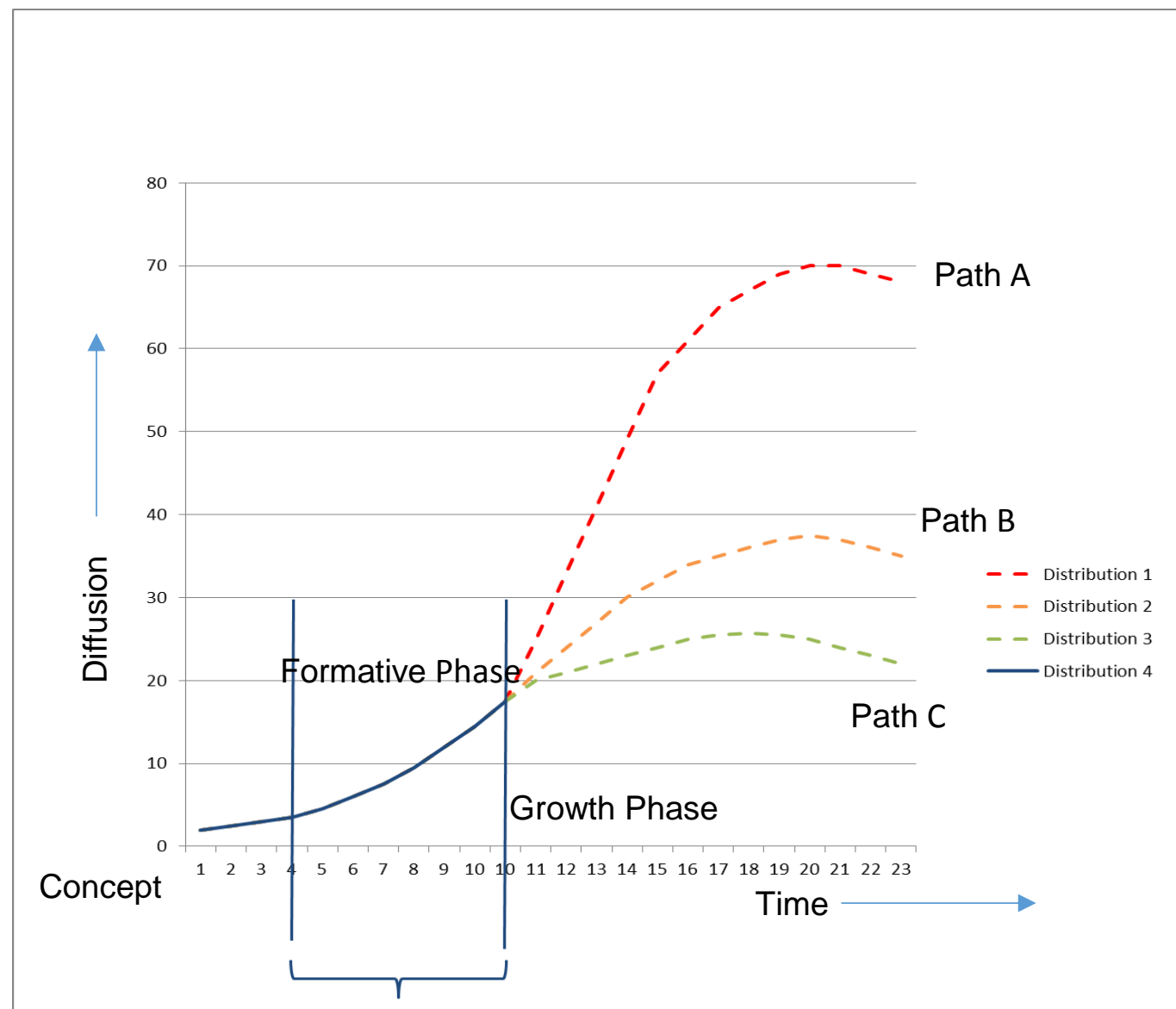


Fig. 2: Potential diffusion paths of breakthrough technologies

The definition proffered by Shah \& Ward (2007, p. 791) that 'lean manufacture is an integrated socio-technical system whose main objective is to eliminate waste by concurrently reducing or minimizing supplier, customer, and internal variability' stresses the socioeconomic nature of LM and makes it clear that all ecosystem players ought to benefit from LM. In this paper, we develop a series of propositions demonstrating key dimensions underpinning legitimation of AM. We contend that should AM achieves deep and broad diffusion, it will not only reduce process waste (which current LM practices allow) but eliminate waste, extending the opportunity to jobbing, batch and some mass production processes (see Fig. 1).

These propositions are of help to future researchers as they can be tested empirically. They are also of help to policy makers and practitioners as they offer critical pointers to key decisions underpinning legitimation of AM.

\subsection{Establishing path ' $A$ ' trajectory}

An extensive search of literature yielded little on magnitude of full diffusion. Here, we propose a methodology for establishing additive manufactured product diffusion representing path ' $A$ ' in Figure 2. We suggest the most useful measure is the market share of additive manufactured products in each key sector. According to Ford (2014) the key sectors for additive manufactured goods were: motor vehicles; aerospace; industrial / business machines; 
medical / dental; consumer products; and architectural. With the technical advances in material and binding techniques the list of key sectors will grow. In each of these sectors there is a nursery market for additive manufactured products (Ford, 2014). For example, in the case of medical / dental sector additive manufactured product accounted for 0.04 per cent of total shipment in 2011 and in the case of aerospace industry 0.02 per cent of total shipments in 2011 (Ford, 2014). We were not able to find more up-to-date share of market mainly because these were part of consultants' report and cost of access to them was prohibitive. However, several such reports published in 2017 provided a headline figure for the total size of additive manufactured products. These were circa 8 times of the market size Ford (2014) stated for 2011. This suggests the market share of additive manufactured products is less than 1 per cent of total shipments.

We propose that path ' $A$ ' trajectory is accomplished when the market share of additive manufactured products hits double digit in a sector. The actual size of market share depends on industry contingencies and difficult to specify at this point. We suggest that it may vary between 10 to 30 per cent.

\section{Triple Bottom Line of Sustainability and Additive Manufacturing}

To assess the potential of $\mathrm{AM}$ as a sustainable enabler, we propose to use the triple bottom line framework of Elkington (1997) and consider economic, environmental and social aspects as the three pillars of sustainable change (Fig. 3). 


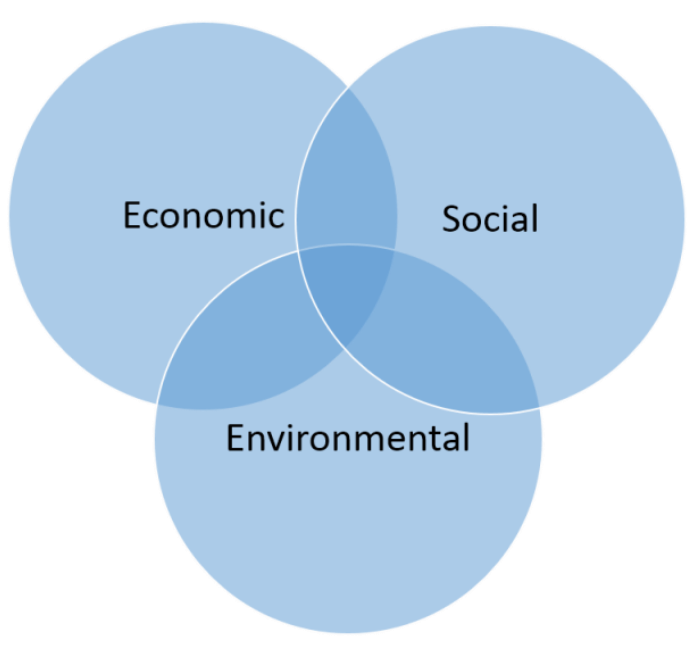

Fig. 3: Pillars of sustainability (adapted from Elkington, 1997)

\subsection{Environmental potential of additive manufacturing}

According to the International Energy Outlook report (IEO, 2016), the industrial sector consumes 54 per cent of the total energy produced globally, with an annual average growth rate of 1.2 per cent. The current levels of consumption and the projected growth rates fly in the face of the Paris Agreement (Accord de Paris) - an agreement within the United Nations Framework Convention on Climate Change (UNFCCC) dealing with greenhouse gas emissions mitigation, adaptation and finance, starting in the year 2020. Hence, the sector needs to search for transformative sustainable changes, and AM is considered a key enabler facilitating this transformation if fully adopted. However, and as previously discussed, its penetration is still too low to have a meaningful global environmental impact.

The potential of AM to contribute to environmental sustainability is well referenced in the extant AM literature (Basiliere et al., 2017; Columbus, 2015; D’Aveni, 2015). The benefits are not restricted to the reduction in waste central to the LM concept but extend to externalities of manufacturing and products as the following examples demonstrate.

1. The production of more optimal and lightweight geometries that improve combustion and fuel consumption. Since the US Aviation Federation cleared, in 2015, the use of 3D-printed 
temperature sensors for engine jets, the aeronautic industry has been intensively exploring and developing new uses of AM. The printing of nozzles by GE, in its Alabama factory, for the LEAP jet engines (alluded to previously) is a good example of how AM can potentially reduce both the externalities of the manufacturing process and product. The new nozzles combine 20 parts in one 3D-printed part, reducing weight by 25 per cent, which translates into a reduction of 20 per cent in fuel consumption and 10 per cent increase in horsepower. They have announced 12,200 unit sales of the new engines, valued at $\$ 170$ billion (General Electric, 2017). Additionally, Airbus has reported the adoption of bionic 3D-printed materials for the A320 plane interiors. Currently developed for the partition between the galley and passenger area, the company estimates that if implemented to the entire cabin and the current backlog of A320 planes, it could save up to 465,000 metric tonnes of $\mathrm{CO}_{2}$ emissions per year (Airbus, 2016).

2. Extend the durability of products thanks to quality improvements in mass customisation and easier access to 3D-printed parts. As an example, the customised mass production of hearing aid shells deploying AM technology allows for better fitting into a patient's ear canal, and results ultimately in devices that are more durable. Similar cases are found in dentistry and prosthetic applications (Diegel et al., 2010). Another incipient example of longer-lasting products rests on the strategy of some companies, such as Hoover, that have started to release the specifications of some replacement parts and use 3D-printing in the manufacture of these parts, extending the life of older products, reducing the pressure on landfill sites and reducing replacement costs for less well-off consumers (Ford et al., 2015).

3. Finally, AM is also contributing actively to the prototyping and development of new green technologies such as fuel cells (Guo \& Leu, 2013). Additionally, AM itself is inherently a green technology, as it can easily transform plastic from everyday products into raw material for new 3D-printed objects. (Ford et al., 2015). 
Despite examples such as the ones presented above and the potential and current expectations of AM, there is a scarcity of studies quantifying the real impact of AM on sustainability (Sreenivasan et al., 2010). This is a weakness because a greater number of systematic studies, and their dissemination, is critical to the process of legitimation as will be discussed later. In this respect, policy makers, practitioners and academics can make a substantial and decisive difference. Moreover, the first global study on AM and sustainability estimates that AM - as being used today - would only have a residual impact of approximately 5 per cent in the reduction of industrial $\mathrm{CO}_{2}$ emissions and energy consumption by 2025 (Gebler et al., 2014). The main reason for this low impact rests on the existence of a nursery market for AM produced goods - specific high-value-added niche products. Gebler et al.'s (2014) study concludes that the impact would be more significant if (a) AM were deployed in mass markets such as the automotive market; and (b) the social impact of AM on the workforce were fully addressed. These suggest that the full environmental impact of AM will only be realised if the scale of adoption is both wide (in terms of both industrial and geographic dispersion) and deep (accounting for a meaningful percentage of industrial output). This in turn is dependent on its legitimation path.

\subsection{Social impact of additive manufacturing}

We concur with Gebler et al.'s (2014) view that sidestepping the social dimensions of AM is detrimental to its broad and deep diffusion. In developing strategies and policies for the wider adoption of AM, the societal impact of AM needs to be fully taken into account. Although we have not found any study analysing the social implications of AM, the potential issues arising are not necessarily unknown. Every disruptive technology capable of transforming the existing paradigms poses the same questions: How will the change affect existing markets and institutions? And, how many jobs will be superseded by the technology? To give two examples: 
the transition to textile machines in the nineteenth century and the shift from horse-drawn carriages to automobiles in the early twentieth century raised the same questions and were received with major doses of resistance among incumbents (Geels, 2005; Miller \& Atkinson, 2013). One of the few uncontested certainties in economics is that technological innovation is the factor that contributes most to economic growth (Solow, 1956; Schumpeter, 1962). Miller \& Atkinson (2013) have also demonstrated that the net impact of technological change on the labour market is positive. Past experience suggests that AM is likely to provide an engine for growth and its net impact on job losses may be marginal because of its potential for:

1. reshoring production to deindustrialised developed countries, offering a balance to the backlash against globalisation. Countries, such as the UK, are establishing task forces to seize the opportunities that AM can bring to revitalise industry (Foresight, 2013)

2. improving productivity, which in turn is likely to lead to higher wages and increased disposable income resulting in job creation

3. lowering of production costs and the resultant lower prices, boosting consumption and increasing output, which in turn will boost direct and indirect employment. However, rebound effects will need to be taken into consideration as we are moving into sustainable change

4. making possible the production of goods and services that are currently unfeasible or unaffordable, creating new markets and employment

5. creating a thriving industry for AM machine manufacturers and suppliers, which in turn will be a new source of employment.

As we point out, policy makers, industrialists and academics have a significant role in systematically analysing the potential social impact of AM, reducing the anxiety and resistance to its introduction among the critical ecosystem players and society at large. 


\subsection{Economic benefits of additive manufacturing}

As was pointed in section 4.2, in the long-term AM will aid creation of new markets and will lower production costs for existing products and services. Nowadays, AM is seen as a cost-competitive manufacturing process in niches such as dentistry and prosthetics (Reeves et al., 2011). In other cases, such as in the aerospace industry, although AM-produced parts attract a higher price by comparison than the same parts produced using traditional manufacturing processes, the reduction in weight and the flexibility of the geometry offsets the higher purchasing price resulting in significant operating cost reductions (Wohlers \& Caffrey, 2015). These business cases represent a good quantifiable evidence base on the viability of niche developments of AM as a sustainable innovation. As indicated, AM is a breakthrough technology in its formative phase (see Fig. 2). In many sectors, there is a nursery market for AM-produced products (for example, the aeronautics industry where a small number of parts are printed) and in some industries, there is a bridging market (for example, the prosthetic industry where production has reached an intermediate level) but AM-produced products have not penetrated mass markets. In the next section, we offer a set of propositions for the legitimation of AM, a critical step to enhance the scale of adoption to levels that will make this breakthrough technology truly relevant in the effort to reduce waste and harmful externalities of manufacturing and products as well as boosting sustainability. Table 4 provides a summary of the impact of LM and potential impact of AM on the physical environment and sustainability for different manufacturing processes using categories of waste that LM aims to reduce/eliminate. The table is an extension of Tables 2 and 3, and draws on and summarises points made in the first four sections.

Table 4: Comparative impact of LM and AM on the waste, physical environment and sustainability
Category of
Lean Manufacturing
Additive Manufacturing
waste 


\begin{tabular}{|c|c|c|c|c|c|c|}
\hline & Jobbing & Batch & Mass & Jobbing & Batch & Mass \\
\hline Defects & Minimal & Low & High & High & High & Low/Medium \\
\hline $\begin{array}{l}\text { Unnecessary } \\
\text { inventory }\end{array}$ & Minimal & Low & High & High & High & Low/Medium \\
\hline Waiting & Minimal & Low & High & High & High & Low/Medium \\
\hline Transportation & Minimal & Low & High & High & High & Low/Medium \\
\hline $\begin{array}{l}\text { Inappropriate } \\
\text { processing }\end{array}$ & Minimal & Low & High & High & High & Low/Medium \\
\hline $\begin{array}{l}\text { Over } \\
\text { production }\end{array}$ & Minimal & Low & Medium & High & High & Low/Medium \\
\hline $\begin{array}{l}\text { Unnecessary } \\
\text { motions }\end{array}$ & Minimal & Low & High & High & High & Low/Medium \\
\hline $\begin{array}{l}\text { Physical } \\
\text { environment } \\
\text { externality }\end{array}$ & Minimal & Low & $\begin{array}{l}\text { Low / } \\
\text { Medium }\end{array}$ & Medium & Medium & Low \\
\hline Sustainability & Minimal & Low & $\begin{array}{l}\text { Low / } \\
\text { Medium }\end{array}$ & Medium & Medium & Low \\
\hline
\end{tabular}

\section{Considerations for the legitimation of Additive Manufacturing}

In section 3 we pointed out the overlap between LM and AM in relation to elimination of waste arising from non-value-added activities. Lean production relies on soft-technology (routines) and process design to reduce waste predominately among manufactures deploying mass production techniques. Additive manufacturing is technological breakthrough capable of eliminating waste due to non-value-added activities extending the LM ideals beyond traditional mass producers to firms deploying jobbing or batch processes as well mass producers hitherto not attracted to LM. It is also important to point out that AM has the potential to impact the supply chain of assemblers. We content that AM overlaps with and advances the primary goals of LM to its ultimate frontier. As such AM subsumes LM and as indicated previously we use these two terms interchangeably.

However, as discussed in the previous section, it is premature to consider AM as a fullyfledged paradigm taking forward and extending the reach of LM and sustainable manufacturing. The current level of activity, concentrated on high-added-value niches, 
suggests that AM is in its formative stage (see Fig. 2) - the space between proven concept and large-scale adoption. The main drivers of AM are economic and environmental. In both cases, systematic evidence to support the legitimation process is lacking. The social impact cannot be divorced from these considerations - and perception of a negative social impact, at best, will slow down the process of broad and deep-scale spread and, at worse, it will stop widespread diffusion. In addition, barriers to wide and deep-scale diffusion persists in relation to each of the three pillars of sustainable development. On the economic side, these include: reliability and accuracy of equipment and processes; the absence of clear and widely accepted standards increasing the cost and complexity of transactions, such as software compatibility and communication across AM machines; lack of innovative business models; difficulty to capture customer needs and input in the design process; affordability of equipment and materials; absorptive capacity, for example, in relation to selection of materials etc. (Ford, 2014; Huang et al., 2015). In relation to the environmental pillar, reported barriers relate to the lack of a methodology to evaluate AM emissions and energy consumption leading to contradictory evidence, and the lack of knowledge and regulation regarding the toxicity and impact of new raw materials and solvents used by AM technology (Huang et al., 2013). Finally, the social barriers concentrate around resistance to change established routines and practices in organisations (Wohlers \& Caffrey, 2015) and the instability created by the uncertainty around the impact on the workforce (Gebler et al., 2014).

Hence AM is at a crucial stage, where gaining legitimation is a necessary condition in overcoming the 'liability of newness' (Stinchcombe \& March, 1965). Many sound breakthrough innovations fail to fully achieve their potential at the formative stage prior to acquiring sufficient critical mass (Geroski, 2000). Segway offers an interesting case in point. It was designed as a revolutionary new transportation option, but it has been relegated to the realm of the mall cop and tour group. A breakthrough technology fails by not reaching the scale 
of adoption that makes it relevant. Ketokivi and Schroeder (2004) argue that LM acquired wide levels of adoption because organisations started to mimic what successful competitors were doing. Although mimicry is a well-known pattern in innovations diffusion research (Rogers, 2010), it comes about once the innovation has been legitimated and has successfully overcome the uncertainties of its formative phase.

Whether AM succeeds or fails to diffuse fully will depend on the level of acceptance by direct and indirect stakeholders. Breakthrough technologies by themselves do not create new paradigms (Bijker et al., 2012; Christensen et al., 2004; Tidd \& Bessant, 2009). On the contrary, they shape their trajectories in a process of gaining socio-political strength through stakeholder acceptance and institutional alignment, developing appropriate business models (Adner, 2002; Christensen et al., 2004) and identifying strategic windows of opportunity for the new paradigm (Geels, 2005).

As an example, a strategic window of opportunity for AM could be manufacturing SMEs normally reliant on jobbing or batch process. According to Achanga et al. (2006) SMEs are more averse to introducing LM because they lack the necessary resources, knowledge and absorptive capacity. The challenge faced by SMEs is heightened by the sheer volume of routines and processes required to support the implementation of LM. Additive manufacturing does away with complex process redesign or introduction of complex routines bridging the resource, knowledge and absorptive capacity gap hampering SMEs ability to benefit from LM. However, as previously discussed, AM needs to legitimate, and be perceived by SMEs (in this example) as an accepted manufacturing paradigm. We contend that legitimation is a key to preventing innovation failure facilitating transition from the formative to the growth phase. To this end we synthesis the literature aiming to develop propositions aiding the legitimatisation of AM below. As it was pointed out previously AM subsumes LM and its legitimation resulting in broad and deep diffusion will aid eradication / significant reduction in process waste of not 
only mass production process but also jobbing and batch process.

Van der Panne et al. (2003) conducted an extensive literature review examining causes of innovation failure. They conclude that cultural resistance in the form of embedded routines and interpretative barriers play a critical role in encouraging opposition to the adoption of innovation. Routines are a key aspect of organisational behaviour as they structure processes, activities and organisational capabilities (Nelson \& Winter, 1982). Additive manufacturing like any breakthrough technology is likely to face resistance. Wohlers and Caffrey (2015) suggest the main barrier to the broad adoption of AM is cognitive myopia and legacy routines. Rogers (2010), in line with Van der Panne et al. (2003), argues that innovations that are not compatible with prevailing norms, values and beliefs of the social system where they operate will be adopted at a slower pace (if at all) than those innovations that do not represent a clash with respect to the prevailing norms and practices. This consideration is particularly relevant if, as in the case of AM, the nature of the innovation is not incremental, but architectural or radical (Tushman \& Anderson, 1986). The arguments proffered lead us to suggest the following proposition:

Proposition 1: The gap between prevailing industrial beliefs, norms and practices and those proposed by AM influence its adoption. Hence, a small gap will increase the likelihood and pace of a successful transition from formative to growth phase.

Together with the existing routines, values, norms etc., another important source of resistance might arise in the form of powerful actors - typically incumbents - opposing or delaying the development of the innovation, especially if the innovation is perceived as a threat to their secured positions and business models. This pattern has been well observed in the 
development of sustainable technologies in the energy sector (Bergek et al., 2008b; Hellsmark \& Jacobsson, 2012). In other industries, such as healthcare, scholars have also pointed out the role of institutional forces in hampering the adoption of innovations that may threaten the status quo (Christensen et al., 2000; Topol, 2012). This source of resistance might be of particular importance for AM. As discussed in Section 4, AM can have important social and economic impacts, such as the reshoring of production to deindustrialised countries or in the emergence of new business models in industries such as appliances and parts.

Ultimately, as Winner (1980) states, artefacts have politics, particularly in innovations that come with new rules of the game that can shake existing power structures. As Mitchell et al. (1997) contend: 'power may be tricky to define, but it is not that difficult to recognize.'

Following on from the above, a second proposition regarding the legitimation of AM is asserted:

Proposition 2: Powerful actors might block or delay the transition from the formative to the growth phase particularly if new proposed business models are perceived as a threat for incumbents' business models.

The extant literature (reviewed previously) suggest that institutional frameworks in the form of norms, values and beliefs, as well as the different interests of actors in the system, can positively or negatively influence the transition of AM to its growth phase, hence, it stands to reason to assume that proponents of innovation should undertake different strategies to legitimate it. To identify plausible legitimation strategies, this study will make use of organisational studies on legitimation, as they have largely examined how firms and industries acquire, maintain or repair legitimacy. Suchman, (1995) defines legitimacy as 'a generalized perception or assumption that the actions of an entity are desirable, proper, or appropriate within some socially constructed system of norms, values, beliefs, and definitions' (p. 574). Suchman proposes three different strategies to acquire legitimacy: conform to the existing 
norms and practices; select an audience that will support the new practices; or manipulate by creating new audiences and new legitimating beliefs. Conforming to existing beliefs, norms and practices is the more convenient way to gain legitimacy (Zimmerman \& Zeitz, 2002), but paradoxically breakthrough innovations come to create new rules of the game. As a main strategy, conforming can undermine the potential of the innovation.

However, it can become an adequate entry strategy before more favourable ones can be put in place. For this reason, we prefer to denominate this strategy as strategic conformance. The strategy of selecting appropriate audiences presents some analogies to what in innovation theory is referred to as niche management (Geels, 2005; Kemp et al., 1998). Finally, manipulating by creating new audiences and new legitimating beliefs is the ideal of innovators, but might not be straightforwardly applicable if routines, norms and values have prevailed for a long time in the system, or if opposing forces from actors and institutions perceive the innovation as a threat. We contend that acquiring legitimacy is more likely to follow an iterative process - oscillating back and forth - of conformation and selection before new beliefs, norms, values and business models can be accepted. This leads to the third proposition:

Proposition 3: Different industrial contexts require different legitimation strategies. These strategies will vary in their radicalness according to existing institutional constraints mainly in the form of embedded norms and practices and the level of resistance from relevant actors in the system (Propositions 1 and 2).

As discussed, legitimation is an iterative process directed by the institutional framework and the interests of system participants. Therefore, policy makers and innovation proponents should look for levers that contribute to creating legitimacy and eventually move - if necessary - from conforming to more manipulative strategies. The literature on technological innovation system (TIS) suggests the creation of advocate coalitions and networks of entrepreneurs or system builders offers an effective way to overcome the barriers to establishing a new 
institutional set of norms, values or business models (Bergek et al., 2008a; Bergek et al, 2008b). Although these networks and coalitions are necessary, they might not be sufficient. As Hellsmark (2010) points out, opponents can form coalitions and networks too. To identify deeper mechanisms of legitimation, it is necessary to examine different dynamics of legitimation.

Suchman (1995) classifies legitimation into three main types according to differentiated behavioural dynamics: pragmatic, moral and cognitive. Pragmatic legitimacy relates to self-interest. In the context of a technological innovation such as AM, pragmatic legitimacy refers to the self- or appropriable interest that stakeholders might have in its development. Moral legitimacy relates to how desirable and appropriate the novelty is according to prevailing norms and values. Finally, cognitive legitimacy accounts for how the new technology provides meanings, beliefs and taken-for-granted routines that make it meaningful.

Suchman (1995) suggests that legitimacy becomes stronger and more difficult to obtain as one moves from the pragmatic to the moral to the cognitive. Align to this, Laifi \& Josserand (2016) state that cognitive legitimation represents the final stage of the process, once pragmatic and normative legitimation dynamics have paved the way for new knowledge and new routines to be taken for granted. Therefore, pragmatic and moral legitimation are a pre-requisite to acquiring cognitive legitimation. Pragmatic legitimation -referring to appropriable interests is typically presented in the form of technology assessments and cost-benefit analysis (Bergek et al., 2008b). However, if assessments are based on the expectations generated by the future potential of the technology - as might be the case for technologies in their formative phase this can have a negative impact on audiences that can interpret it as a self-interested act, leading, as Suchman (1995) argues, to self-promoter paradoxes. Whereas expectations provide a shared vision about a desirable future, and might also fulfil a performative function attracting attention 
and investment (Bergek et al., 2008a; Borup et al., 2006), they need to be contrasted with high quality evidence to avoid self-promoter paradoxes and recurrent disappointments that can result in a credibility damage (Brown \& Michael, 2003), and consequently in a loss of moral legitimacy. Therefore, creating adequate legitimation conditions for pragmatic and moral legitimation requires sustainment of expectations supported with evidence. This leads to our fourth proposition:

Proposition 4: Providing quality evidence on the benefits of AM contributes to the development of pragmatic and moral legitimacy.

Finally, to ultimately reach cognitive legitimacy and take for granted new knowledge, we propose to develop it as a collective endeavour among TIS actors. Co-creation and sharing of knowledge provide multiple advantages towards legitimation. Chief among them is the opportunity to provide credible evidence regarding the technology (see Proposition 4). Moreover, co-creation of knowledge among technologists and final users opens the possibility of modifying and adjusting the innovation to solve real problems and needs. As Ram (1987, pp. 208-212) points out: 'the most important characteristic for an innovation to be successful is its amenability to modification. The modification to be made would depend on what caused the resistance: if the resistance was due to lack of compatibility; the modification would attempt to improve the compatibility of the innovation; if the perceived relative disadvantage caused the resistance. It would need to reduce it... '. Finally, co-creation of knowledge speeds up learning curves. From this, Proposition 5 follows as:

Proposition 5: Guiding the direction of knowledge development through collaborative knowledge creation among actors helps to build legitimacy.

In conclusion, to answer the question, 'what main levers need to be manipulated to move AM from the formative to growth phase?', one should consider not only the creation of 
advocate coalitions and networks to communicate the advantages of the innovation and lobby in favour of institutional changes; but also, as Propositions 4 and 5 suggest, manage expectations through evidence of quality and co-creation of knowledge with the final beneficiaries of the innovation. Together our propositions help to overcome legitimation barriers.

\section{Summary}

Lean manufacturing is predicated on the concept that any activity/action that fails to create value for customers is waste or muda and should be reduced/removed (Bevilacqua et al., 2017). Therefore, essentially the goal of LM is to reduce/remove waste. The concept of muda has been extended to encompass damage to the physical environment and overuse of natural resources in recognition of societal concern for the environment (Simboli et al., 2014). There is broad consensus on the definition and sources of process waste (Jasti \& Kodali, 2015; Liker, 2004).

Lean manufacturing is an attempt to incrementally improve key manufacturing performance metrics by systematically reducing/eliminating waste (Biazzo et al., 2016). The outcomes LM seeks to attain are centred on structure (e.g. power distribution, workforce autonomy - famously on the Toyota's shop floor operators have the right to stop the assembly line), process (e.g. line balancing, cellular manufacturing, etc.), and routines (six sigma, standardisation, modularisation, total productive maintenance, etc.) rather than the underlying hard technology. The levers used by LM to attain its objectives are such that it is impractical to eliminate waste but its proper use can significantly reduce waste (see Fig. 1). Its implementation involves the deployment of a matrix of routines, as well as varying degree of process and structural change (Jasti \& Kodali, 2015; Marodin \& Saurin, 2013), with increasing complexity, which may account for outcomes lagging expectations (Marodin \& Saurin, 2015). 
The context offering the best fit for LM is characterised by high demand, a stable operating environment, low and controllable process variability, low product variety and a repetitive process (Browning \& Sanders, 2012). Hence, mass production processes offer the best fit for LM. Not surprisingly, Olhager \& Prajogo (2012) conclude that LM is more effective where manufacturers are making to forecast (high volume, stable demand) than when they are making to order. These points suggest that while some of the tools and practices of LM can be applied to jobbing and batch manufacture processes, LM is best suited to mass production.

Additive manufacturing (AM) is a revolutionary technology building products layer by layer. It offers a radical departure from conventional manufacturing where products are made by cutting, bending and bashing material. The technology has the potential to change the face of manufacturing heralding the arrival of the Third Industrial Revolution. Additive manufacturing is in its formative phase - the space between the concept and growth/extensive adoption (Bergek et al., 2008a). The supply and demand for AM manufactured goods resembles that of a nursery market (Bergek et al., 2008a). Most breakthrough technologies fail at this stage (Stevens and Burley, 1997). Failure occurs because the breakthrough technology does not reach the scale of adoption that would make it relevant. We highlight the weaknesses of AM that potentially can prevent its deep and widespread diffusion.

In this paper, we demonstrate how a technological approach in the shape of AM can potentially help broad swathes of manufacturing firms, those deploying jobbing and batch processes as well as some additional mass producers, to eradicate/drastically reduce process waste or muda central to the LM concept. We contend that the waste produced by the manufacturing process lies along a continuum - at one end lies high-process waste associated with the conventional approaches to manufacturing and at the other end, zero process waste (Fig. 1). We have offered arguments drawing on the literature that LM reduces process waste, while AM has the potential to eliminate process waste (Fig. 1). We follow this by 
demonstrating how a reduction in waste can reduce environmental damage and AM's potential in this respect. But critically, AM can further reduce negative environmental externalise of products and manufacturing processes. We also establish a link between AM and the triple bottom line concept by demonstrating how AM has the potential to make a positive contribution to each dimension of the triple bottom line. We contend that potentially AM can take LM to it ultimate destination by eliminating waste (Fig. 1).

The problem is that AM is in its formative stage and whether or not it becomes truly relevant depends on its scale of adoption. We use the legitimation concepts to propose a series of propositions in support of AM legitimation. These propositions pave the way for detailed empirical research. Moreover, they offer policy makers and practitioners pointers as to the actions required to facilitate broad and deep diffusion of AM.

\section{Conclusions}

Additive manufacturing, as articulated, is a disruptive innovation in its formative phase with a potential of extending the reach of lean manufacturing and sustainability. Many promising technologies fail at this stage by not reaching high scales of adoption. Additive manufacturing, despite its great economic and environmental promise and possible social benefits, may fail to diffuse deeply and remain a niche technology. This would be detrimental to securing a sustainable base for manufacturing and attaining the goals of LM.

In order to acquire deep and broad levels of adoption, AM needs to overcome uncertainty by gaining legitimation in new markets. We develop a series of propositions focusing on the clash of the technology with existing norms and practices or the opposition of certain actors to its development. These propositions aid the legitimatisation of AM critical for its full diffusion.

This is a conceptual paper demonstrating how AM represents a breakthrough 
sustainable innovation to LM approach, and how it can be legitimated to enable attainment of elimination of what LM concept considers waste. Clearly, there is need for empirical research examining how AM can contribute to the economic and social aspects of sustainability and to what extent its adoption will represent the frontier of LM capabilities. Further research helping policy makers to make the correct decisions is of utmost importance. 


\section{References}

Achanga, P., Shehab, E., Roy, R., \& Nelder, G. (2006). Critical success factors for lean implementation within SMEs. Journal of Manufacturing Technology Management, 17(4), 460-471.

Adner, R., 2002. When are technologies disruptive? A demand-based view of the emergence of competition. Strategic Management Journal, 23(8), 667-688.

Airbus, 2016. Pioneering bionic 3D printing.

http://www.airbus.com/newsroom/news/en/2016/03/Pioneering-bionic-3Dprinting.html.

Baker, P., 2002. "Why is lean so far off?” Works Management, 55, 26-29.

Basiliere, P., Shanler, M., Smith, E., Burton, J., Halpern, M., 2017. Predicts 2018: 3D Printing and Additive Manufacturing. (ID: G00342398). Retrieved from Gartner database.

Bate, P., 1984. The impact of organizational culture on approaches to organizational problem-solving, organization studies, 5(1), 43-66.

Berente, N., Lee, J., 2014. How process improvement efforts can drive organisational innovativeness. Technology Analysis \& Strategic Management, 26(4), 417-433.

Bergek, A., Jacobsson, S., Carlsson, B., Lindmark, S., Rickne, A., 2008a. Analyzing the functional dynamics of technological innovation systems: a scheme of analysis. Research Policy, 37(3), 407-429.

Bergek, A., Jacobsson, S., Sandén, B.A., 2008b. 'Legitimation' and 'development of positive externalities': two key processes in the formation phase of technological innovation systems. Technology Analysis \& Strategic Management, 20(5), 575-592.

Berman, B., 2012. 3-D printing: the new industrial revolution. Business Horizons, 55(2), $155-162$. 
Bevilacqua, M., Ciarapica, F.E., De Sanctis, I., 2017. Lean practices implementation and their relationships with operational responsiveness and company performance: an Italian study. International Journal of Production Research, 55(3), 769-794.

Biazzo, S., Panizzolo, R., De Crescenzo, A.M., 2016. Lean management and product innovation: a critical review. In: Chiarini, A., Found, P., Rich, N., (Eds.). Understanding the lean enterprise. Switzerland: Springer, 237-260.

Bijker, W.E., Hughes, T.P., Pinch, T., Douglas, D.G., 2012. The social construction of technological systems: new directions in the sociology and history of technology. MIT Press.

Blanchard, D., 2007. Census of U.S. Manufacturers - Lean Green and Low Cost. Industry Week, October.

Bleda, M., Del Rio, P., 2013. The market failure and the systemic failure rationales in technological innovation systems. Research policy, 42(5), 1039-1052.

Borup, M., Brown, N., Konrad, K., Van Lente, H., 2006. The sociology of expectations in science and technology. Technology Analysis \& Strategic Management, 18(3-4), 285-298.

Brown, N., Michael, M., 2003. A sociology of expectations: retrospecting prospects and prospecting retrospects. Technology Analysis \& Strategic Management, 15(1), 3-18.

Browning, T.R., Sanders, N.R., 2012. Can innovation be lean? California Management Review, 54(4), 5-19.

Carlsson, B., Stankiewicz, R., 1991. On the nature, function and composition of technological systems. Journal of Evolutionary Economics, 1(2), 93.

Christensen, C.M., Anthony, S.D., Roth, E.A., 2004. Seeing what's next: using the theories of innovation to predict industry change. Harvard Business Press.

Christensen, C. M., Bohmer, R., \& Kenagy, J. (2000). Will disruptive innovations cure health 
care?. Harvard business review, 78(5), 102-112.

Columbus, L., 2015. 2015 Roundup of 3D printing market forecasts and estimates. Forbes. http://www.forbes.com/sites/louiscolumbus/2015/03/31/2015-roundup-of-3d-printingmarket-forecasts-and-estimates/\#54d939bb1dc6 [accessed 30 Jan 2017].

D’Aveni, R., 2015. The 3-D printing revolution. Harvard Business Review, 41-8.

Diegel, O., Singamneni, S., Reay, S., Withell, A., 2010. Tools for sustainable product design: additive manufacturing. Journal of Sustainable Development, 3(3), 68.

11(3), 147-62. http://dx.doi.org/10.1016/0048-7333(82)90016-6.

Economist, The, 2012. The third industrial revolution. http://www.economist.com/node/21553017 [accessed 30 Jan 2017].

Economist, The, 2016. 3D printing produces a curious lightweight motorcycle, 26 May 2017. Economist, The, 2017a. Additive manufacturing3D printers start to build factories of the future, 29 June 2017.

Economist, The, 2017b. Adidas's high-tech factory brings production back to Germany, 14 January 2017.

Economist, The, 2017c. Making things anew: 3D printing transforms the economics of manufacturing, 1 July 2017.

Elkington, J., 1997. Cannibals with forks. The triple bottom line of 21st century business. Capstone Publishing Ltd.

Ford, S.L., 2014. Additive manufacturing technology: potential implications for US manufacturing competitiveness. Journal of International Commerce and Economics. http://www.usitc.gov/journals/Vol_VI_Article4_Additive_Manufacturing_Technolog y.pdf [accessed 30 Jan 2017].

Ford, S., Despeisse, M., Viljakainen, A., 2015. Extending product life through additive manufacturing: the sustainability implications. Global Cleaner Production and 
Consumption Conference, Sitges, Barcelona, Spain, 1-4 November 2015.

Foresight, 2013. The future of manufacturing: a new era of opportunity and challenge for the UK. Project report. The Government Office for Science, London.

FT, 2016. Five industries under threat from technology.

\section{https://www.ft.com/content/b25e0e62-c6ca-11e6-9043-7e34c07b46ef.}

Gebler, M., Uiterkamp, A.J.S., Visser, C., 2014. A global sustainability perspective on 3D printing technologies. Energy Policy, 74, 158-167.

Geels, F.W., 2005. Technological transitions and system innovations: a co-evolutionary and socio-technical analysis. Edward Elgar Publishing.

General Electric, 2017. An epiphany of disruption: GE additive chief explains how 3D printing will upend manufacturing. https://www.ge.com/reports/epiphany-disruptionge-additive-chief-explains-3d-printing-will-upend-manufacturing/.

Geroski, P.A., 2000. Models of technology diffusion. Research Policy, 29, 603-625.

Guo, N., Leu, M.C., 2013. Additive manufacturing: technology, applications and research needs. Frontiers of Mechanical Engineering, 8(3), 215-243.

Hellsmark, H., 2010. Unfolding the formative phase of gasified biomass in the European Union: the role of system builders in realising the potential of second-generation transportation fuels from biomass. Chalmers University of Technology.

Hellsmark, H., Jacobsson, S., 2012. Realising the potential of gasified biomass in the European Union - policy challenges in moving from demonstration plants to a larger scale diffusion. Energy Policy, 41, 507-518Hines, P., Holweg, M., Rich, N., 2004. Learning to evolve: a review of contemporary lean thinking. International Journal of Operations \& Production Management, 24(10), 994-1011.

Huang, S.H., Liu, P., Mokasdar, A., Hou, L., 2013. Additive manufacturing and its societal impact: a literature review. International Journal of Advanced Manufacturing 
Technology, 67(5-8), 1191-1203.

Huang, Y., Leu, M.C., Mazumder, J., Donmez, A., 2015. Additive manufacturing: current state, future potential, gaps and needs, and recommendations. Journal of Manufacturing Science and Engineering, 137(1), 014001.

IEO, 2016. International Energy Outlook Report. http://www.eia.gov/outlooks/ieo/.

Jasti, N.K., Kodali, R., 2015. Lean production: literature review and trends. International Journal of Production Research, 53(3), 867-885.

Kemp, R., Schot, J., Hoogma, R., 1998. Regime shifts to sustainability through processes of niche formation: the approach of strategic niche management. Technology Analysis \& Strategic Management, 10(2), 175-198.

Ketokivi, M.A., Schroeder, R.G., 2004. Strategic, structural contingency and institutional explanations in the adoption of innovative manufacturing practices. Journal of Operations Management, 22(1), 63-89.

Kietzmann, J., Pitt, L., Berthon, P., 2015. Disruptions, decisions, and destinations: enter the age of 3-D printing and additive manufacturing. Business Horizons, 58(2), 209-15.

Krafcik, J.F., 1988. Triumph of the lean production system. Sloan Management Review, $30(1), 41-52$.

Laïfi, A., Josserand, E., 2016. Legitimation in practice: a new digital publishing business model. Journal of Business Research, 69(7), 2343-2352.

Liker, J.K., 2004. The Toyota way: 14 management principles from the world's greatest manufacturer. New York: McGraw-Hill.

Marodin, G.A., Saurin, T.A., 2013. Implementing lean production systems: research areas and opportunities for future studies. International Journal of Production Research, 51(22), 6663-6680.

Marodin, G.A., Saurin, T.A., 2015. Managing barriers to lean production implementation: 
context matters. International Journal of Production Research, 53(13), 3947-3962.

Marvel, J.H., Standridge, C.R., 2009. Simulation-enhanced lean design process. Journal of Industrial Engineering and Management, 2, 90-113.

Miller, B., Atkinson, R.D., 2013. Are robots taking our jobs, or making them? Information Technology and Innovation Foundation, September. http://www2.itif.org/2013-arerobots-taking-jobs.pdf [accessed 30 Jan 2017].

Mitchell, R.K., Agle, B.R., Wood, D.J., 1997. Toward a theory of stakeholder identification and salience: defining the principle of who and what really counts. Academy of Management Review, 22(4), 853-886.

NCUB, 2016. Additive manufacturing could revolutionise the clothing industry. National Centre for Universities and Business. http://www.ncub.co.uk/success-stories/additivemanufacturing-could-revolutionise-the-clothing-industry.html [accessed 30 Jan 2017].

Nelson, R.R., Winter, S.G., 1982. An evolutionary theory of economic change. Cambridge, MA: Belknap Press.

Ohno, T., 1989. Toyota Production System. Portland, OR: Productivity Press.

Olhager, J., Prajogo, D.I., 2012. The impact of manufacturing and supply chain improvement initiatives: a survey comparing make-to-order and make-to-stock firms. Omega, 40(2), 159-165.

Pettigrew, A.M., Woodman, R.W., Cameron, K.S., 2001. Studying organisational change and development: challenges for future research, Academy of Management Journal, 44(4), $697-713$.

Ram, S., 1987. A model of innovation resistance. ACR North American Advances.

Reeves, P., Tuck, C., Hague, R., 2011. Additive manufacturing for mass customization. In:

Fogliatto, F., da Silveira, G., (Eds.). Mass customization. Springer, 275-289.

Rifkin, J., 2012. The third industrial revolution: how the internet, green electricity, and 3-D 
printing are ushering in a sustainable era of distributed capitalism. World Financial Review, 1.

Rogers, E.M., 2010. Diffusion of innovations. Simon and Schuster.

Schumpeter, J.A., 1962. Capitalism, socialism and democracy. New York: Harper \& Row.

Shah, R., Ward, P.T., 2007. Defining and developing measures of lean production. Journal of Operations Management, 25(4), 785-805.

Simboli, A., Taddeo, R., Morgante, A. 2014. Value and wastes in manufacturing. An overview and a new perspective based on eco-efficiency. Administrative Sciences (2076-3387), 4(3), 173-191.

Slack, N., Chambers, S., Johnston, R., 2009. Operations and process management: principles and practices for strategic impact. Prentice Hall.

Solow, R.M., 1956. A contribution to the theory of economic growth. The Quarterly Journal of Economics, 70(1), 65-94.

Sreenivasan, R., Goel, A., Bourell, D., 2010. Sustainability issues in laser-based additive manufacturing. Physics Procedia, 5, 81-90.

Stevens, G. A., Burley, J., 1997. 3,000 raw ideas = 1 commercial success! ResearchTechnology Management, 40(3), 16-27.

Stinchcombe, A.L., March, J., 1965. Social structure and organizations. Advances in Strategic Management, 17, 229-259.

Suchman, M.C., 1995. Managing legitimacy: strategic and institutional approaches. Academy of Management Review, 20(3), 571-610.

Tidd, J., Bessant, J., 2009. Managing innovation: integrating technological, market and organizational change. Wiley.

Topol, E. J., \& Hill, D. (2012). The creative destruction of medicine: How the digital revolution will create better health care (p. 2). New York: basic books. 
Tushman, M. L., Anderson, P., 1986. Technological discontinuities and organizational environments. Administrative Science Quarterly, 439-465.

Van der Panne, G., Van Beers, C., Kleinknecht, A., 2003. Success and failure of innovation: a literature review. International Journal of Innovation Management, 7(03), 309-338.

Winner, L. (1980). Do artifacts have politics?. Daedalus, 121-136.

Wohlers, T.T., Caffrey, T., 2015. Wohlers report 2015: 3D printing and additive manufacturing state of the industry annual worldwide progress report. Wohlers Associates.

Womack, J. P., Jones, D.T., Roos, D., 1990. The machine that changed the world. New York: Rawson Associates.

Womack, J.P., Jones, D.T., 1996. Lean thinking: banish waste and create wealth in your corporation. New York: Simon \& Schuster, 305-311.

Yadav, O.P., Nepal, B.P., Rahaman, M.M., Lal, V., 2017. Lean implementation and organizational transformation: a literature review. Engineering Management Journal, 29(1), 2-16.

Zimmerman, M.A., Zeitz, G.J., 2002. Beyond survival: achieving new venture growth by building legitimacy. Academy of Management Review, 27(3), 414-431. 